\section{Estudio in vitro de la actividad antibacteriana del extracto de Erythroxylum coca sobre bacilos negro pigmentados}

\author{
In vitro study of the antibacterial activity of Erythroxylum coca \\ extract on black-pigmented bacillus
}

\begin{abstract}
Resumen
Objetivo: Determinar si existe actividad antibacteriana del extracto de hoja de coca (Erythroxylum coca), sobre bacilos negro pigmentados (BNP). Materiales y método: Se emplearon dos pruebas: Test de Difusión en Agar y Dilución en medio líquido. Las cepas de BNP fueron aisladas de muestras tomadas de bolsas periodontales de pacientes con enfermedad periodontal atendidos en la Facultad de Odontología de la Universidad Nacional Mayor de San Marcos. El extracto hidroalcohólico de hoja de coca fue obtenido de la Empresa Nacional de la Coca (ENACO). Resultados: La primera prueba difusión en agar indicó sensibilidad nula (-) para la mayor parte de las concentraciones evaluadas, y sensibilidad límite (sensibilidad: +) para las concentración de $12,5 \%$ y 100\%. Los resultados de la sensibilidad por dilución determinaron una concentración mínima del extracto capaz de inhibir el crecimiento de dicha bacteria, $100 \%$ (concentración mínima inhibitoria), y a las concentraciones de $12,5 \%$ y $6,25 \%$ se observa una repotenciación del efecto antibacteriano del extracto. Conclusiones: El extracto hidroalcohólico de hoja de coca, sí presenta una actividad antibacteriana frente a BNP, a las concentraciones de 100\% y 12,5\%. Palabras clave: Bacterias anaerobias gramnegativas; Erythroxylon coca; Antibacterianos.
\end{abstract}

\section{Abstract}

Objective: To determine whether there is antibacterial activity of coca leaf extract (Erythroxylum coca), on black pigmented bacilli (BPB). Materials and method: Two tests were used: Diffusion Test in Agar and Dilution in liquid medium. The BPB strains were isolated from samples taken from periodontal pockets of patients with periodontal disease treated at the Faculty of Dentistry of the Mayor National University of San Marcos. The hydroalcoholic extract of coca leaf was obtained from the National Company of Coca (ENACO). Results: The first agar diffusion test indicated null sensitivity (-) for most of the concentrations evaluated, and limit sensitivity (sensitivity: +) for the concentrations of $12.5 \%$ and $100 \%$. The results of the dilution sensitivity determined a minimum concentration of the extract capable of inhibiting the growth of this bacterium, $100 \%$ (minimum inhibitory concentration), and at the concentrations of $12.5 \%$ and $6.25 \%$ a repotentiation of the antibacterial effect of the extract. Conclusions: The hydroalcoholic extract of coca leaf, does present an antibacterial activity against BPB, at concentrations of $100 \%$ and $12.5 \%$

Keywords: Gram-negative anaerobic bacteria; Erythroxylon coca; Anti-bacterial agents.

\section{Artículo Original}

\author{
Carmen Enciso Deza 1,a, Donald Ramos \\ Perfecto ${ }^{2, b}$ \\ 1 Facultad de Odontología. Universidad Nacio- \\ nal Mayor de San Marcos. Lima, Perú. \\ 2 Departamento Académico de Ciencias Básicas. \\ Facultad de Odontología. Universidad Nacio- \\ nal Mayor de San Marcos. Lima, Perú. \\ a Cirujano Dentista \\ b Magíster en Microbiología
}

Correspondencia:

Carmen Paola Enciso Deza

Correo electrónico: pao.enciso@hotmail.com Facultad de Odontología, UNMSM. Calle Germán Amézaga 375. Lima 1, Perú.

Coautor:

Donald Ramos Perfecto

dramosp@unmsm.edu.pe

Conflicto de intereses: Los autores declaran no tener conflictos de interés.

Fuente de financiamiento: Autofinanciado.

Fecha de recepción: 26/04/17

Fecha de aceptación: 31/05/17

\section{Introducción}

En la actualidad, la enfermedad periodontal representa una de las enfermedades bucales más prevalentes del Perú, afectando aproximadamente al $85 \%$ de la población ${ }^{1}$. Su etiología y desarrollo se ha relacionado por ańos con la presencia de microorganismos periodontopatógenos, los cuales producen la destrucción de los tejidos de soporte del diente; entre estas bacterias, se encuentran los bacilos negro pigmentados (BNP), los cuales son bacterias anaerobias estrictas, gramnegativas, que habitan el fondo de bolsas periodontales ${ }^{2,3}$, destacándose entre estos los pertenecientes a la familia Bacteroidaeceae $^{4}$, según el Manual de Bacteriología Sistémica de Bergey (Bergey`s Manual of Systematic Bacteriology) ${ }^{5}$, representados por los géneros Porphyromonas ${ }^{6}$ y Prevotella. Han sido fuertemente relacionadas por estudios previos, con la periodontitis ${ }^{3,7}$. Se ha comprobado que a una localización más posterior, existe mayor prevalencia de BNP, además éstas aumentan en número a mayor profundidad de la bolsa periodontal ${ }^{3}$.

En estudios sobre alteraciones hormonales y composiciones microbianas en pacientes gestantes, se mencionan a los BNP como las especies que sufren un incremento en el fluido crevicular, específicamente Prevotella intermedia y Porphyromonas gingivalis, debido a 
que las hormonas sexuales femeninas (progesterona y estradiol) estarían aumentadas en el fluido crevicular y éstas serían fuente de nutrientes para dichas bacterias ${ }^{5,8}$.

El tratamiento de esta enfermedad consiste en la remoción y control de placa supra y subgingival ${ }^{9} \mathrm{y}$ el uso de agentes antimicrobianos (colutorios medicados, terapia antibiótica, entre otros). Pero aproximadamente entre el 30 y el $85 \%$ de las cepas de Prevotella intermedia y Porphyromonas gingivalis son productoras de betalactamasas ${ }^{10}$. La prevalencia de resistencia a tetraciclinas y macrólidos se sitúa en torno al $30-50 \%$ y $80-95 \%$ respectivamente, siendo la azitromicina el macrólido más activo frente a bacilos gramnegativos anaerobios ${ }^{11}$. Entre el 5 y $25 \%$ de las cepas son resistentes a clindamicina y menos del 5\% a metronidazol ${ }^{12,13}$. La producción de betalactamasas por estos BNP genera en ellas una resistencia a la penicilina y a la amoxicilina.

Las investigaciones actuales, dan énfasis al estudio de sustancias naturales, especialmente a aquellas que contienen polifenoles, como la hoja de coca, para así determinar si poseen propiedades farmacológicas con efecto antibacteriano ${ }^{14}$. Se debe destacar que los fármacos a base de derivados de productos naturales presentan una inmensa ventaja respecto a los tratamientos químicos. En las plantas los principios activos siempre están biológicamente equilibrados por la presencia de sustancias complementarias que van a potenciarse biológicamente entre sí, de forma tal, que en general no se acumulan en el organismo, y sus efectos indeseables son limitados ${ }^{15,16}$. Hoy en día las sustancias derivadas de plantas constituyen aproximadamente el 25\% de las medicinas. El uso de la hoja de coca data de tiempos muy antiguos, los Incas la llamaban "hoja sagrada" por sus virtudes curativas. Los pobladores de la región andina del Perú la siguen utilizando ya sea masticándola, en infusión, mate, emplastos, y cataplasmas ${ }^{17}$. Tiene propiedad anestésica y antidepresiva; haciendo énfasis que bajo la forma de hoja de coca, ésta no produce toxicidad o dependencia. Tiene propiedad multivitamínica por la presencia de vitamina A, complejo B y vitamina $\mathrm{E}$, como también presencia de micronutrientes tales como calcio, hierro, zinc, magnesio, potasio, etc ${ }^{18}$.

Ramos ${ }^{15}$ determinó la actividad antibacteriana del extracto hidroalcohólico de hoja de coca (Erythroxylum coca), sobre la cepa ATCC 33277 de Porphyromonas gingivalis, dando como resultado que dicho extracto tiene sensibilidad nula (-) para la mayor parte de las concentraciones evaluadas, y sensibilidad límite (sensibilidad: +) para la máxima concentración del extracto (100\%) sobre el crecimiento de dicha bacteria. Además, se determinó la concentración mínima del extracto, capaz de inhibir el crecimiento de dicha bacteria, cuyo valor fue de $6,25 \%$.

Borrovic ${ }^{19}$ realizó un estudio experimental, para determinar el efecto antibacteriano del extracto alcohólico de la hoja de Erythroxylum coca sobre flora mixta oral, determinó que sí existe un efecto antimicrobiano positivo a las concentraciones de 250, 500, $1000 \mathrm{y}$ $1500 \mathrm{ug} / 20 \mathrm{ul}$ de dicho extracto frente a los cultivos de flora mixta salival. Además, se encontró que a mayor concentración del extracto, mayor es el efecto antimicrobiano obtenido.

Minaya ${ }^{20}$ realizó un estudio para determinar la actividad antibacteriana del extracto etanólico de la hoja de Erythroxylum novogranatense var. truxillense frente a Streptococcus mutans y Lactobacillus casei, obtenido por la técnica de maceración alcohólica. Se determinó que dicho extracto tuvo una mayor actividad antibacteriana que el alcohol al $96 \%$.

Se realizó el presente estudio, con la finalidad de conocer si existe actividad antibacteriana del extracto de hoja de coca sobre BNP. Para esto se recurre a dos pruebas; la primera, el Test de difusión en Agar y la segunda, la prueba de dilución en medio líquido, resultados positivos de las pruebas podrían generar un posible producto que actúe como antiséptico oral.

\section{Materiales y método}

Es un estudio experimental, prospectivo e in vitro. El extracto de Erythroxylum coca fue obtenido de la Empresa Nacional de la Coca (ENACO S.A.), y posteriormente diluido con alcohol etílico $96^{\circ}$ hasta obtener soluciones de 0,78\%, 1,56\%, 3,13\%, 6,25\%, 12,5\%, $25 \%, 50 \%$ y $100 \%$. Dichas diluciones fueron conservadas en frascos de vidrio oscuro, a temperatura ambiente, sin exponerse al sol, como sugieren las especificaciones técnicas del producto - Condiciones de almacenamiento.

Se trabajó con cultivos puros de BNP, obtenidos de muestras de bolsas periodontales de pacientes con enfermedad periodontal atendidos en la Facultad de Odontología de la Universidad Nacional Mayor de San Marcos, los cuales previo a la toma de muestra firmaron su consentimiento informado para dicho procedimiento.

Las muestras fueron tomadas con conos de papel número 30 ó 40, los cuales se introdujeron en la bolsa periodontal de la pieza seleccionada, previo sondaje, por un tiempo aproximado de $60 \mathrm{se}$ gundos, quedando así el cono embebido, posteriormente se los introdujo en el medio de transporte Brain Heart Infusion (BHI), para ser cultivadas en un lapso de tiempo no mayor de 24 horas. Luego de estos se tomó una alícuota y se sembró en placas Petri que contenían el medio de Agar Sangre Suplementado (Agar Schaedler) y se llevó a incubar en un sistema generador de Anaerobiosis (Anaerocult ${ }^{\oplus} \mathrm{A}$ ) por 7 - 14 días, a 37 ${ }^{\circ} \mathrm{C}$, hasta observar el crecimiento de las colonias. De estas colonias fueron repicadas en nuevas placas aquellas que presentaron las siguientes características: colonias circulares, convexas, de tamaño aproximado de $0,5-2 \mathrm{~mm}$, lisas y pigmentadas de color oscuro, gramnegativa, para su posterior resiembra para purificar la muestra (Figura 1); igualmente, se llevó a incubar en un sistema generador de anaerobiosis por 7 - 14 días, a $37^{\circ} \mathrm{C}$, hasta observar el crecimiento de las colonias.

La prueba de la actividad antibacteriana, se llevó a cabo mediante el Test de difusión en Agar con discos. Primero, se procedió a tomar algunas colonias de BNP del cultivo que previamente se había realizado, y se las suspendió en un Caldo de BHI, obteniendo una turbidez final de 0,5 en la escala de $\mathrm{Mc}$ Farland, que equivale a $0,5 \times 10^{8} \mathrm{UFC/}$ $\mathrm{ml}$. Se diluyó proporcionalmente el extracto de Erythroxylum coca (con alcohol etílico $96^{\circ}$ ) en ocho concentraciones $(1 / 1,1 / 2,1 / 4,1 / 16,1 / 32,1 / 64$, $1 / 128,1 / 256)$.

Se realizó por quintuplicado el Test de difusión en Agar, cada uno de los cua-

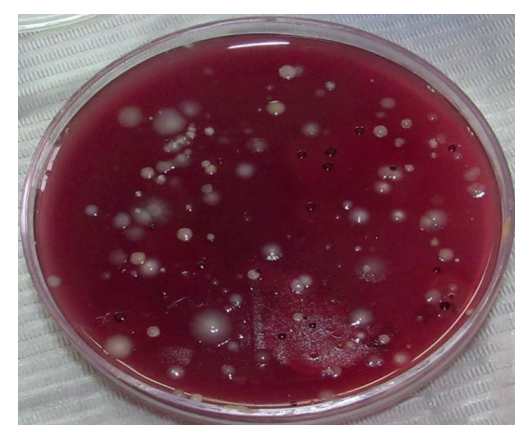

Figura 1. Crecimiento bacteriano con características típicas BNP. Para posterior resiembra, la flecha seńala una colonia de BNP. 
les contenía 10 discos: ocho discos que portaban las ocho diferentes concentraciones del extracto, un disco conteniendo Clorhexidina 0,12\% (control positivo) y otro conteniendo alcohol etílico $96^{\circ}$ (control negativo); cada disco fue cargado con $20 \mu \mathrm{L}$ con las diferentes concentraciones de extracto y de las sustancias control, distribuidos equidistantes sobre el Agar Schadler previamente sembrado con los BNP, todas las placas fueron incubadas por 7 - 14 días, a $37^{\circ} \mathrm{C}$, en un ambiente anaerobio. Luego del tiempo indicado, se procedió a la medición de los halos de inhibición del crecimiento bacteriano en cada placa, utilizando para ello un calibrador pie de rey. Se ordenaron los resultados y se registraron (Figuras 2 у 3$)$.

La determinación de la concentración mínima inhibitoria (CMI) se llevó a cabo mediante un Test de Dilución en medio líquido, para lo cual se preparó 10 tubos de ensayo, cada uno conteniendo $2,8 \mathrm{ml}$ de un medio de cultivo BHI. A cada tubo de ensayo se agregó $100 \mathrm{uL}$ del inoculo bacteriano de BNP, además 100 uL del extracto de Erythroxylum coca al 0,78\%, 1,56\%, 3,13\%, $6,25 \%, 12,5 \%, 25 \%, 50 \%$ y $100 \%$ en forma correspondiente, además se utilizó un tubo con $100 \mathrm{uL}$ de Clorhexidina $0,12 \%$ (control positivo) y otro tubo con $100 \mathrm{uL}$ de alcohol etílico $96^{\circ}$ (control negativo).

Todo este procedimiento se realizó por quintuplicado, y se incubó por 48 horas en un ambiente anaerobio. En cada grupo se evaluaron los 10 tubos, observando el crecimiento bacteriano y se determinó la concentración mínima del extracto capaz de inhibir el crecimiento bacteriano. Cuando esta lectura pasaba de un crecimiento (turbidez) a otro con ausencia de crecimiento (claro), esto representó la CMI (Figura 4).

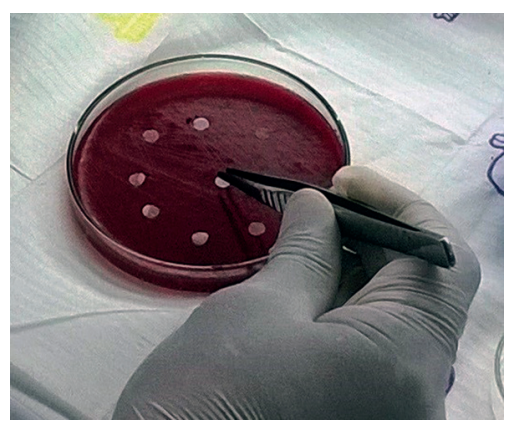

Figura 2. Disposición de los discos de papel embebidos Figura 3. Halos de inhibición del crecimiento de BNP en extracto de E. coca

\section{Resultados}

En la tabla 1, se aprecia que los BNP solo presentan sensibilidad frente al extracto de Erythroxylum coca (sensibilidad límite presenta halos de inhibición de: $9-14 \mathrm{~mm}$ ) en el $60 \%$ de los casos del extracto al $12,5 \%$ y $100 \%$ de concentración.

Al realizar el análisis de los resultados del grupo experimental (extracto de Erythroxylum coca) y el grupo control negativo (Alcohol 96 $)$, mediante la prueba U de Mann-Whitney, se determinó que para las concentraciones $0,78 \%, 1,56 \%, 3,13 \%, 25 \%$ y $50 \%$ del extracto, no existe una diferencia estadísticamente significativa $(p>0,05)$; pero para los resultados de las demás concentraciones $(6,25 \%, \quad 12,5 \% \quad y$ $100 \%)$, si existe una diferencia estadísticamente significativa $(p<0,05)$. Se determina que la menor concentración del extracto de Erythroxylum coca, cuyos resultados presentan una diferencia

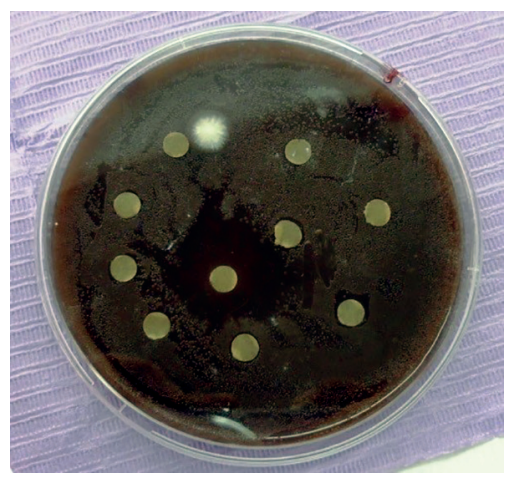

Figura 3. Halos de inhibición del crecimiento de BNP. estadísticamente significativa respecto al grupo control negativo $(\mathrm{p}<0,05)$, fue de $6,25 \%$.

En la tabla 2, se observa que no hubo crecimiento de BNP en la concentración de 100\% de extracto de Erythroxylum coca. En el 100\% de los casos restantes sí hubo crecimiento de BNP en las diferentes concentraciones $0,78 \%$, $1,56 \%, 3,13 \%, 6,25 \%, 12,5 \%$, 25\% y $50 \%$ del extracto de Erythroxylum coca. Pero se observa una repotenciación del efecto antibacteriano del extracto de Erythroxylum coca a las concentraciones de $12,5 \%$ y $6,25 \%$.

Esto permitió determinar un análisis de estimación lineal entre las concentraciones de Erythroxylum coca y el crecimiento de BNP, mostrando una recta con una pendiente pronunciada ( $\mathrm{m}$ : - 1,2143) desde una concentración de $0,78 \%$ hasta $100 \%$ del extracto en estudio. Se observó una relación inversa entre la variable independiente (Erythroxylum coca) y el indicador de la variable

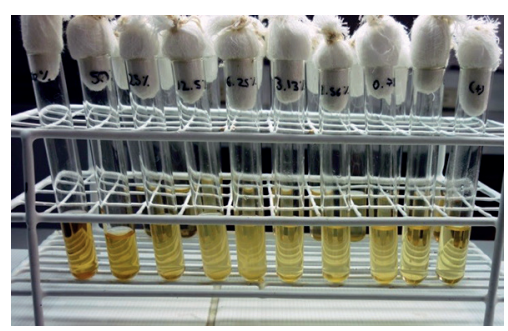

Figura 4. Crecimiento de BNP. Test de Dilución en Medio Líquido

Tabla 1. Actividad antibacteriana del extracto de Erythroxylum coca sobre BNP

\begin{tabular}{llllllllllll}
\hline \multicolumn{10}{c}{ Concentración del extracto de Erythroxylum coca } \\
\hline HALOS & $\begin{array}{c}0,78 \% \\
n(\%)\end{array}$ & $\begin{array}{c}1,56 \% \\
\mathrm{n}(\%)\end{array}$ & $\begin{array}{c}3,13 \% \\
\mathrm{n}(\%)\end{array}$ & $\begin{array}{c}6,25 \% \\
\mathrm{n}(\%)\end{array}$ & $\begin{array}{c}12,5 \% \\
\mathrm{n}(\%)\end{array}$ & $\begin{array}{c}25 \% \\
\mathrm{n}(\%)\end{array}$ & $\begin{array}{c}50 \% \\
\mathrm{n}(\%)\end{array}$ & $\begin{array}{c}100 \% \\
\mathrm{n}(\%)\end{array}$ & $\begin{array}{c}\mathrm{C}(-) \\
\mathrm{n}(\%)\end{array}$ & $\begin{array}{l}\mathrm{C}(+) \\
\mathrm{n}(\%)\end{array}$ \\
\hline S. nula: $8 \mathrm{~mm}$ & $5(100)$ & $5(100)$ & $5(100)$ & $5(100)$ & $2(40)$ & $5(100)$ & $5(100)$ & $2(40)$ & $5(100)$ & $0(0)$ \\
S. límite: 9-14mm & $0(0)$ & $0(0)$ & $0(0)$ & $0(0)$ & $3(60)$ & $0(0)$ & $0(0)$ & $3(60)$ & $0(0)$ & $5(100)$ \\
S. media: 15-19mm & $0(0)$ & $0(0)$ & $0(0)$ & $0(0)$ & $0(0)$ & $0(0)$ & $0(0)$ & $0(0)$ & $0(0)$ & $0(0)$ \\
Sumamente sensible: $>20 \mathrm{~mm}$ & $0(0)$ & $0(0)$ & $0(0)$ & $0(0)$ & $0(0)$ & $0(0)$ & $0(0)$ & $0(0)$ & $0(0)$ & $0(0)$ \\
Total & $5(100)$ & $5(100)$ & $5(100)$ & $5(100)$ & $5(100)$ & $5(100)$ & $5(100)$ & $5(100)$ & $5(100)$ & $5(100)$ \\
\hline
\end{tabular}

Tabla 2. Relación entre el crecimiento de aislados de BNP y las diferentes concentraciones del extracto de Erythroxylum coca

\begin{tabular}{lcccccccc}
\hline Crecimiento & \multicolumn{7}{c}{ Concentración del extracto de Erythroxylum coca } \\
BNP & $0,78 \%$ & $1,56 \%$ & $3,13 \%$ & $6,25 \%$ & $12,5 \%$ & $25 \%$ & $50 \%$ & $100 \%$ \\
$(+)$ & 0 & 0 & 3 & 5 & 4 & 1 & 3 & 0 \\
$(++)$ & 3 & 3 & 2 & 0 & 1 & 4 & 2 & 0 \\
$(+++)$ & 2 & 2 & 0 & 0 & 0 & 0 & 0 & 0 \\
$(-)$ & 0 & 0 & 0 & 0 & 0 & 0 & 0 & 5 \\
\hline
\end{tabular}


dependiente (crecimiento de BNP). El valor obtenido para el coeficiente de regresión, $r^{2}: 0,576$, indicó que la variable extracto de Erythroxylum coca está influyendo en el crecimiento de los BNP.

\section{Discusión}

Los resultados de esta investigación, no se pueden comparar con resultados de otras investigaciones pues no se han trabajado con BNP, además los extractos de hoja de coca utilizados en los anteriores estudios, difieren entre sí, pues fueron elaborados con diferentes especies y en diferentes dependencias. Para este estudio, ENACO proporcionó un extracto hidroalcohólico cuya elaboración obedece estándares que garantizan la homogeneidad del producto, libre de alcaloides, pudiendo ser la base para la ejecución de futuros estudios relacionados.

El efecto antibacteriano del extracto de Erythroxylum coca, también es sustentado por otros trabajos de investigación como el de Ramos $\mathrm{CA}^{15}$, quien obtuvo un efecto antibacteriano positivo (sensibilidad límite) frente a la cepa ATCC de Porphyromonas gingivalis con una concentración de $100 \%$ en el Test de difusión en agar con discos, y una concentración mínima inhibitoria (CMI) de 6,25\% en el Test de dilución en medio líquido. Si bien, el extracto empleado para dicho estudio también fue obtenido en ENACO, difiere en su composición con el extracto utilizado.

Los estudios de Minaya ${ }^{20}$, Castro ${ }^{17}$, y Vergara ${ }^{21}$ demuestran que el extracto de Erythroxylum coca tiene propiedades antibacterianas sobre distintas cepas presentes en cavidad oral (Staphylococcus, Estreptococos). El estudio de Borrovic ${ }^{16}$ evidenció la acción antibacteriana del extracto alcohólico de Erythroxylum Novogranatense var. Truxillense sobre la flora mixta salival, según los resultados obtenidos existe un efecto antimicrobiano positivo a las concentraciones de 250, 500, 1000 y 1500 ug/ 20 ul del extracto, y se encontró diferencias significativas con respecto al tamaño de los halos de inhibición en las distintas concentraciones utilizadas del extracto. Además, indicó que a mayor concentración del extracto, existe mayor efecto antimicrobiano. Esto difiere en parte de los resultados obtenidos, puesto que sí se observa efecto antibacteriano a la máxima concentración del extracto (100\%), pero también se observa una repotenciación a la concentración de $12,5 \%$. Esto puede ser debido a que el diluyente empleado es alcohol $96^{\circ}$, y al ser diluido junto con el extracto $(5: 1)$, hasta lograr la concentración de 12,5\%, puede lograr un efecto de sinergismo, lo que se refleja en una repotenciación que se evidencia en el incremento del diámetro de los halos de inhibición en el Test de Difusión en Agar.

\section{Conclusiones}

El presente trabajo demostró que el extracto de Erythroxylum coca (hoja de coca), tiene actividad antibacteriana sobre el crecimiento de los BNP. La concentración mínima inhibitoria del extracto hidroalcohólico de Erythroxylum coca sobre el crecimiento bacteriano de BNP fue al 100\%, según la prueba de dilución en medio líquido. Se evidencia en el test de difusión en agar, la actividad antibacteriana del extracto de Erythroxylum coca sobre BNP, dando sensibilidad positiva (sensibilidad límite) a las concentraciones de $12,5 \%$ y $100 \%$ de dicho extracto. La prueba de dilución en medio líquido no evidenció una capacidad antibacteriana marcada, excepto al $100 \%$ de concentración del extracto de Erythroxylum coca, pero sí se aprecia una repotenciación de dicho efecto al $12,5 \%$ y $6,25 \%$ de concentración.

\section{Referencias bibliográficas}

1. Ministerio de Salud del Perú. Prevención para la Salud. (Consultado el 22 de mayo 2017). Disponible en: http://www.minsa.gob.pe/index.asp?op=2\#Prevención para la Salud

2. Guilarte C, Perrone M. Bacterias periodontopatógenas: Bacilos anaerobios gram negativos como agentes etiológicos de la enfermedad periodontal. Acta Odontol Venez. 2005;43(2):198-204.

3. Mombelli A, McNabb H, Lang NP. Black-pigmenting gram-negative bacteria in periodontal disease. I. Topographic distribution in the human dentition. J Periodontal Res. 1991;26(4):301-307.

4. Pérez HL, De Armas CA, Fuentes AE. Prevalencia de enfermedad periodontal y factores de riesgo asociados. Rev Ciencias Médicas. 2011;15(2):53-64.

5. Briceño CE, Pardi CG, Perrone CM. Nuevas especies del género Prevotella y su importancia en el área Odontológica: Revisión de la Literatura. Acta Odontol Venez. 2009;47(4):167-173.

6. Ramos PD, Moromi NH, Martínez CE. Porphyromonas gingivalis:
Patógeno predominante en la periodontitis crónica. Odontol Sanmarquina 2011;14(1):34-38.

7. Manfrin DS. Bacterias anaerobias estrictas de interés bucal. Odonto Moder. 2008;4(46):12.

8. Cabrera YM. Estudio microbiológico de la bacteria Prevotella Intermedia en el surco gingival de gestantes con diferentes grados de placa bacteriana- Hospital Nacional Docente Madre-Niño San Bartolomé. [Tesis Bachiller]. Lima: Universidad Nacional Mayor de San Marcos; 2004.

9. Díaz CA, Vivas RR, Puerta LL, Ahumedo MM, Cabrales SR, Herrera HA. Periodontitis, Porphyromonas gingivalis y su relación con la expresión de quorum sensing. Rev Cub Estomatol. 2010;47(4):404416.

10. Ramos PD, Castro LA, Actividad antibacteriana de Copaifera reticulata "Copaiba" sobre Porphyromonas gingivalis aisladas de pacientes con periodontitis. Odontol Sanmaquina. 2014;17(1):7-11.

11. Oteo A, Herrera D, Figuero E, O'connor A, Gonzalez I, Saenz M. Azithromycin as an adjunct to scaling and root planing in the treatment of Porphyromonas gingivalis associated periodontitis: a pilot study. J Clin Periodontol 2010;37:1005-1015

12. Pfau. EA, Avila-Campos MJ. Prevotella Intermedia and Porphyromonas gingivalis isolated from osseointegrated dental implants: colonization and antimicrobial susceptibility. Braz J Microbiol. 2005;36(3):281-285.

13. Liñares J, Martín-Herrero JE. Bases fármaco-microbiológicas del tratamiento antibiótico de las enfermedades periodontales y periimplatarias. Av Periodon Implantol. 2003;15(3):139-147.

14. Moromi NH, Martinez CE, Ramos PD. Antibacterianos naturales orales: Estudios en la Facultad de Odontología de la Universidad Nacional Mayor de San Marcos. Odontol Sanmarquina 2009;12(1):25-28.

15. Ramos CA. Actividad antibacteriana del extracto de Erythroxylum coca sobre Porphyromonas gingivalis, estudio in vitro. [Tesis] de Bachiller. Fac. Odontol: Universidad 
Nacional Mayor de San Marcos. Lima. 2012.

16. Alvarado VV, Moromi NH. Plantas medicinales: Efecto antibacteriano in vitro de Plantago major L, Erythroxylum novogranatense, Plowman var truxillense y Camelia sinensis sobre bacterias de importancia estomatológica. Odontol Sanmarquina. 2010;13(2):21-25.

17. Castro LA. Composición química del aceite esencial de las hojas de Erythroxylum novogranatense (Morris) "coca", actividad antioxidante y determinación antibacteriana frente a Streptococcus mutans. [Tesis Doctorado]. Lima: Universidad
Nacional Mayor de San Marcos; 2008.

18. Rivier L. Analysis of alkaloids in leaves of cultivated Erythroxylum and characterization ok alkaline substance used during coca chewing. J Ethnopharmacol. 1981;3:313-335.

19. Borrovic RF. Efecto antibacteriano del extracto alcohólico de la hoja de Erythroxylum Novogranatense Var. Truxillense (coca) sobre flora mixta oral. [Tesis Bachiller]. Lima:
Universidad Nacional Mayor de San Marcos; 2006.

20. Minaya FP. Determinación de la actividad antibacteriana "in vitro" del extracto etanólico de la hoja de Erythroxylum novogranatense var truxillense (coca) frente a bacterias orales cariogénicas. [Tesis Bachiller]. Lima: Universidad Nacional Mayor de San Marcos; 2008.

21. Vergara PC. Efecto inhibitorio in vitro del Extracto acuoso y Extracto etanólico de la hoja de Erythroxylum novogranatense var truxillense (coca) sobre el crecimiento de Streptococcus mutans. [Tesis Bachiller]. Trujillo: Universidad Nacional de Trujillo; 2011. 
